\section{Long range PCR}

\section{J. Arnemann}

Abteilung Molekulargenetik, Labor Dr. Wisplinghoff, Köln, Deutschland

\section{Synonym(e) Distanz-PCR}

\section{Englischer Begriff long range PCR}

Definition Die Long range PCR ermöglicht die Amplifikation von größeren und komplexen DNA-Abschnitten von über $30 \mathrm{~kb}$ Länge.

Beschreibung Die klassische PCR-Reaktion (s. D PCR (Polymerase-Kettenreaktion)) amplifiziert sicher DNATargets mit einer durchschnittlichen Länge von 3-4 kb. Bei Amplifikation von größeren Targetlängen unter Standardbedingungen kann wegen vermehrt unspezifischer Reaktionen eine Zunahme der Fehlerrate auftreten. Bei einer Amplifikation größerer Templates von 5-30 kb Länge müssen spezielle (Taq-)Polymerasen oder auch Kombinationen davon mit spezifischen Protokollen eingesetzt werde. Verschiedene
„Long range PCR“-Kits sind kommerziell verfügbar und auf die Amplifikation größerer DNA-Abschnitte zugeschnitten. Zuverlässige Protokolle werden dabei gestellt.

Allgemein gilt, dass der Reaktionsansatz auf Eis zu erfolgen hat und anschließend schnellstmöglich in einen auf $94{ }^{\circ} \mathrm{C}$ vorgeheizten Cycler überführt und das Cycler-Programm gestartet werden muss. Die eingesetzten Primer sollten zwischen $20-40$ bp lang sein und einen GC-Gehalt von 40-60\%, optimalerweise über $50 \%$, sowie einen Schmelzpunkt $\left(\mathrm{T}_{\mathrm{m}}\right)$ von über $60{ }^{\circ} \mathrm{C}$ haben. Bei problematischen Templates mit einem sehr hohen GC-Gehalt empfiehlt sich oftmals eine Zugabe von Additiven, wie z. B. DMSO, Formamid oder einem Spezialmix des Kitherstellers. Im PCR-Protokoll sollte die Elongationstemperatur $68^{\circ} \mathrm{C}$ statt $72{ }^{\circ} \mathrm{C}$ betragen und die Elongationszeit entsprechend der Größe des Templates nach der Faustformel 2,5 s/100 bp individuell berechnet werden.

\section{Literatur}

Cheng S, Fockler C, Barnes W, Higuchi R (1994) Effective amplification of long targets from cloned inserts and human genomic DNA. Proc Natl Acad Sci 91:5695-5699 